(5.1-61). Serum lactate median was 2.1 (0.1-11.2). Neurological findings were determined in $22.4 \%$ of the patients. Normobaric oxygen treatment was given to $75.5 \%$ of the patients, while $24.5 \%$ were given hyperbaric oxygen treatment. A positive correlation was determined between Lactate and COHb levels $(\mathrm{P}=0.01, \mathrm{r}=0.228)$. A negative correlation was determined between Glaskow Coma Scale and $\mathrm{COHb}$ levels ( $\mathrm{p}=0.01, \mathrm{r}=-0.383$ ). Patients with neurological findings had an average $\mathrm{COHb}$ level at $35.7 \% \pm 16$, patients without neurological findings had an average $\mathrm{COHb}$ level at $22.5 \% \pm 7.7$ $(p=0.001)$. Blood lactate level was higher in patients with neurological findings than patients without neurological findings $(p=0.01)$.

Results $\mathrm{COHb}$ level in carbon monoxide poisoning cases is an important indicator for the existence of neurological findings. Since increase in lactate is correlated with the poisoning level and neurological findings, high lactate levels should be taken into consideration.

\section{A RANDOMISED TRIAL OF DEXAMETHASONE VERSUS PREDNISOLONE IN THE TREATMENT OF ACUTE PAEDIATRIC ASTHMA EXACERBATIONS}

doi:10.1136/archdischild-2012-302724.0370

1,2J CRONIN, 1,2S McCoy, ${ }^{1} \mathrm{~S}$ Nally, ${ }^{3} \mathrm{U}$ Kennedy, ${ }^{2} \mathrm{G}$ Crispino-O'Connell, ${ }^{1} \mathrm{~S}$ Walsh, ${ }^{1,2,4} \mathrm{R}$ O'Sullivan. 'Paediatric Emergency Research Unit, Our Lady's Children's Hospital, Crumlin; 'National Children's Research Centre, Our Lady's Children's Hospital Crumlin; ${ }^{3}$ Department of Emergency Medicine, St James's Hospital; ${ }^{4}$ Department of Paediatrics, University College Dublin, Dublin, Ireland

Introduction The aim of this open-label trial is to examine whether a single dose of dexamethasone is non-inferior to a 3-day course of prednisolone in the treatment of exacerbations of asthma in children who attend the Emergency Department (ED).

Methods Participants were identified on ED presentation, eligibility was confirmed and informed consent was obtained. Patients were randomised to receive either a stat dose of oral dexamethasone $0.3 \mathrm{mg} / \mathrm{kg}$ ( $\max 12 \mathrm{mg}$ ) or prednisolone $1 \mathrm{mg} / \mathrm{kg} /$ day ( $\max 40 \mathrm{mg}$ ) for 3 days. Otherwise standard treatment was administered.

Following discharge from the $\mathrm{ED}$, patients were clinically reviewed on Day 4, and by telephone on Day 14 . The primary outcome measure was the Pediatric Respiratory Assessment Measure (PRAM score) at Day 4. Secondary measures include relapse rate, requirement for more steroids, number of salbutamol therapies, and vomiting.

A sample size of 210 subjects will be sufficient to reject the null hypothesis - that the population means of both groups are equal with a probability of 0.9 . The Type I error probability is 0.05 .

Results 201 individual asthma exacerbations (101 prednisolone, 100 dexamethasone) have so far been enrolled. Demographic details and exacerbation severity are equal across both groups. We will complete enrolment in May 2012.

Conclusion The results of this randomised trial may have a significant impact on the management of acute asthma in children. At current rates we will complete recruitment in May 2012 and will present full reults at the conference.

\section{RARE PRESENTATION OF ACUTE DEMYELINATING ENCEPHALOMYELITIS IN A CHILD WITH EXCESSIVE FATIGUE AND SLEEPINESS}

doi:10.1136/archdischild-2012-302724.0371

A Silwal, A Morris. Calderdale and Huddersfield NHS Trust, Leeds, UK

The encephalopathic child is a paediatric emergency and presents a considerable challenge.

We present a 4 year old boy who was admitted with 3 week history of excessive fatigue and sleepiness, waking for only $4-5$ hours a day. He had occasional episodes of vacant stares and "wanted to go home", when was at home.

$\mathrm{He}$ had gastroenteritis after exposure to snails at nursery and was treated for otitis media by general practitioner. There was no history of fever or foreign travel.

He was sleepy with normal neurology and an apthous ulcer over lower lip. He was managed as encephalitis and treated with acyclovir, ceftriaxone and clarithromycin. He had neutrophilia with normal lumbar puncture and viral PCR's.

After a week of admission, he deteriorated with generalized pain, bedwetting, ataxia and upper motor neuron signs. MRI scan showed asymmetric, bilateral white matter changes suggestive of acute demyelinating encephalomyelitis (ADEM) or other viral encephalitis.

Repeat lumbar puncture showed pleocytosis with neutophilia. Viral PCR's were negative. ASOT was raised. MRI with contrast showed $4 \mathrm{~mm}$ high signal focus behind C2 body and C2-3 disk.

After completing a 10 day course of acyclovir, he was started on methyl prednisolone for ADEM and drastically improved. He was discharged after 3-4 days of the treatment with follow up.

This case initiated a lot of discussions- presence of fever to diagnose encephalitis? When to start and stop acyclovir in suspected encephalitis with negative viral PCR's? To start steroids or not why the delay?

\section{ACTIVATED CHARCOAL FOR GHB INTOXICATION IN CHILDREN: AN IN VITRO STUDY}

doi:10.1136/archdischild-2012-302724.0372

'RW Neijzen, ${ }^{2}$ MA Sikma, 'AC Egas, 'FFT Ververs, 'EM van Maarseveen. 'Department of Pharmacy; ${ }^{2}$ Intensive Care, University Medical Centre Utrecht, Utrecht, The Netherlands

Background and Aims Treatment of intentional (mainly by adolescents) and unintentional (mainly by children) intoxications with the increasingly popular drug gamma-hydroxybutyrate (GHB) primarily consists of symptomatic treatment. The usually rapid absorption and the need for intubation argue against activated charcoal (AC) treatment in GHB intoxications. However, the use of AC has been suggested in several guidelines and in literature, but it has never been demonstrated to what extent GHB binds (adsorbs) to AC. Reduction of GHB absorption by AC administration could be clinically relevant, especially in children. Therefore, binding of GHB to $\mathrm{AC}$ in an in vitro model was tested.

Methods Different quantities (2.5, 5, 7.5, or 10 grams) of AC were mixed with a dose of $800 \mathrm{mg} \mathrm{GHB}$ at $37^{\circ} \mathrm{C}$ in $100 \mathrm{~mL}$ simulated gastric ( $\mathrm{pH}$ 1.2) or intestinal ( $\mathrm{pH}$ 7.2) fluid, respectively. Subsequently, after 15 minutes of incubation the $\mathrm{AC}$ was separated from the liquid by centrifugation and the remaining GHB quantified by gas chromatography. $\mathrm{GHB}$ binding to $\mathrm{AC}$ was plotted in a binding curve.

Results Binding of GHB to AC was dose-dependent. At gastric $\mathrm{pH}$, binding was higher than at intestinal $\mathrm{pH}$, with a maximum binding of $84.3 \%$ and $23.3 \%$, respectively, with 10 grams of $\mathrm{AC}$, corresponding with a high adult dose.

Conclusions $\mathrm{AC}$ has GHB binding capacity, which is $\mathrm{pH}$ dependent. In case of (un)intentional intake of GHB by children, rapid treatment with AC may be considered.

\section{CHARACTERISTICS AND COMPLICATIONS IN ORAL CAUSTIC INGESTION IN CHILDREN}

doi:10.1136/archdischild-2012-302724.0373

${ }^{1} \mathrm{M}$ Rafeey, ${ }^{2} \mathrm{M}$ Shoaran, ${ }^{3} \mathrm{~F}$ Javadzadeh. ${ }^{1}$ Pediatric Gastroenterology, Tabriz University of Medical Sciences, Liver \& Gastrointestinal Research Center; ${ }^{2}$ Pediatric, Tabriz University of Medical Sciences; ${ }^{3}$ Dentistry, Tabriz University of Medical Sciences, Aras International University, Tabriz, Iran 